\title{
Miscellany
}

\section{Locum consultant opportunity}

A locum post will be available from 5 December 1994 for about 12 weeks. This well-established post is in general adult community psychiatry. There are adequate beds avallable, a day hospital and a highly experienced community mental health team. Any psychiatrist who is both available and interested (for example, senior registrars in the third or fourth years of training) should contact Dr Larry Culliford, Consultant Psychiatrist, South Downs Health NHS Trust, Aldrington House, Hove Community Mental Health Centre, 35 New Church Road, Hove BN3 4AG (telephone 0273 778383; fax 0273 733775).

\section{Job share}

Anyone interested in psychotherapy training at senior registrar level as part of a job share is invited to contact Dr Katy Bowen, 1 Stanhope Place, London W2 2HB (telephone 071262 6444).

\section{Coping with Depression audio tape}

A self-help programme on audio tape, designed to bring coping skills to people suffering from depression, has been launched by the Defeat Depression Campaign. Based on cognitive therapy techniques, the programme is avallable as a double cassette pack with printed support materials (price £11.99 inclusive of VAT and postage) or a shortened version on a single 40 minute tape (price $£ 7.55$ inclusive). It is available from 'Depression Pack/Tape', PO Box 1, Wirral L47 7DD. (Cheques must be payable to WLAP). Credit card telephone: 0516320662.

\section{Mental Health Foundation grants}

The Learning Disabilities Committee of the Mental Health Foundation has two types of grants available for 1994-95: small scale grants of up to $£ 5,000$ for organisations which aim to affect local service provision and improve the quality of life of those with learning disabilities, and larger grants for innovative community care and research projects. Completed applications should be returned by 30 September 1994. Further information: Elizabeth Gale, Secretary, Learning Disabilities Committee, Mental Health Foundation, 37 Mortimer Street, London W1N 7RJ (telephone 071580 0145).

The Mental Health Foundation has also allocated a new grant of $£ 25,000$ to the UK Hearing Voices Network based in Manchester to further develop an understanding of volce-hearing experiences and to promote ways of encouraging self-help methods for individuals to cope with the voices.

\section{New publications}

SANE, the charity which fights for better care, treatment and understanding of schizophrenia, depression and other serious mental illness, has published six booklets entitled Schizophrenia: the forgotten tllness; Depression and Manic Depression; Anxiety, Phobia and Obsession; Psychological Methods of Treatment; Medical Methods of Treatment and Alcohol, Drugs and Mental Illness. They are the first in a series of 12 for people living with mental illness, their families and carers. A limited supply is available free of charge from Munro \& Forster Healthcare Public Relations, 37 Soho Square, London W1V 5DG.

MIND has published Understanding Eating Distress, the latest in its 'Understanding ...' series. Copies of the booklet cost 45p and are avallable from MIND Publications, Granta House, 15-19 Broadway, London E15 4BQ. Please enclose a large stamped addressed envelope. MIND has also produced a new benefits supplement for its $A-Z$ of Welfare Benefits for People with a Mental Health Problem. It lists the new benefits rates which came into force on 11 April 1994. The update is available free of charge with a stamped addressed envelope to MIND Publications. The complete guide, $A-Z$ of Welfare Benefits for People with a Mental Health Problem, including the update sheet, is avallable from MIND Publications, priced $£ 2.50$ plus $10 \%$ postage and packing. 